\title{
PSYCHOMETRIC INDICATORS OF THE SOCIAL AND EMOTIONAL LONELINESS SCALE FOR ADULTS - SHORT VERSION (SELSA-S) IN BULGARIA

\author{
Nataliya Alexandrova ${ }^{1}$, Liliya Babakova $^{2}$
}

\begin{abstract}
This article examines the psychometric indicators of Social and Emotional Loneliness Scale for Adults, the short version (SELSA-S; DiTommaso, Brannen, \& Best, 2004). The scale contains 15 items, divided into three scales: social loneliness, emotional loneliness, and romantic loneliness. The survey was attended by 1713 persons over 60 years of which were 1042 women and $671 \mathrm{men}$; and 383 of whom were in early-to-middle adulthood (20-55 years). The results showed high-reliability ratios for both the full scale $(\alpha=0.825)$ and the three subscales $(\alpha=0.727-0.845)$ versions. The factor analysis showed a four-factor structure of the scale. There were also statistically significant correlations between the three subscales. It was found that social and emotional loneliness had the strongest influence among older people. Therefore, it was necessary to create more opportunities for satisfactory communication, forms, and functioning of social contacts. It was found that the romantic loneliness had the strongest influence on younger people, i.e., they experienced significantly the lack of a partner by them or dissatisfaction with him.
\end{abstract}

UDC Classification: 005, 378, DOI: https://doi.org/10.12955/pss.v1.38

Keywords: psychometric indicators, validation, Social and Emotional Loneliness Scale, Aging, Adulthood

\section{Introduction}

Personality loneliness is one of the most current topics today. The rapidly changing conditions of life, the unpredictability of the socio-political and the present economic situation in Bulgaria affect the area of interpersonal communication and interactions between people. According to studies and national statistics in Britain, loneliness has become an epidemic among early adulthood (Neill-Hall, 2013; Davidson \& Rossall, 2015). The modern human consciousness is formed and developed in conditions of increasing information flow in the process of interaction among different groups of people. All this causes the person to be in permanent readiness for numerous, but not long-lasting social interactions that only multiply the effect of loneliness. Older people are at no less risk of experiencing loneliness. They are exposed to and worried about the danger of losing a spouse or losing a lot of their friends and that this will negatively affect their well-being. Older people (80+ years of age) understand and appreciate the meaning of "loneliness" in more nuanced ways than people of other age groups. For them, it is associated with a reduction in activity presupposed by a reduction in their capacity to work or limits on their mobility, rather than by a lack of social contacts (Alexandrova, 2015).

\section{Literature review}

Recently, publications on loneliness have increased in Europe and the United States, but neither gives a clear definition of loneliness (Shevchenko, Miheeva, 2014)

Loneliness is often seen as a symptom or predictor of the onset of mental problems. It is a complex and unique experience for everyone. There are many opinions and links that guide the survival of this experience. Accordingly, the prevention and intervention is strictly individual (Mushtaq et al., 2014; Yanguas et al., 2018).

This problem raises the necessity to create or adapt and validate a suitable tool to determine whether, how, when, and why people experience loneliness. In this way, it will be possible to diagnose the harmful effects of loneliness on humans. A good scale for measuring loneliness can help psychologists determine to what extent loneliness is a norm, is pre-pathological, or is pathological (Tiwari, 2013). Once the impact of loneliness on a person's psychological well-being is determined, he or she will be able to receive adequate help before it becomes pathological. Creating or adapting a qualitative instrument for measuring loneliness will allow setting referent values for the different degrees to which loneliness threatens a person's psychological health. Medicine reference values are considered as a set of values that the doctor uses to interpret the patient's test results. It is proposed that an appropriate test for measuring loneliness should be established, to introduce referent values that consultative and clinical psychologists could use to interpret human psychological health and to propose preventive measures. When creating or adapting and validating a suitable scale for measuring loneliness, it is possible to introduce a reference range for people: (i) who are not affected by the state

\footnotetext{
${ }^{1}$ International Business School, Sofia, Bulgaria, alexandrovan@yahoo.com

${ }^{2}$ Academy of Music, Dance and Fine Arts, Faculy of Musical Education, Plovdiv, Bulgaria, babakova_lilia@abv.bg
} 
of loneliness; (ii) who are at psychological risk from the effects of loneliness; and (iii) who are affected by loneliness to the extent that they need the help of a clinical psychologist.

There are various tests for measuring loneliness (Alexandrova, 2019). However, most of them measure the general level of loneliness, not its variants. This article will study the psychometric capabilities of SELSA-S (DiTommaso, Brannen \& Best, 2004), the Social and Emotional Loneliness Scale for Adults - Short Form. It is a short version of the original 37-item scale (DiTomasso \& Spinner, 1993). The reduced version consists of 15 items, distributed in a 7-dimensional Likert-type scale (1 - disagree to 7 - completely agree) and contains three subscales: social loneliness, emotional loneliness, and romantic loneliness. The Social Loneliness scale measures the extent to which one feels part of a social group. It measures relationships with friends and contains five items. The Emotional Loneliness Scale assesses feelings and is concerned with family relationships. It also contains five items. The Romantic Loneliness Scale measures the extent to which the subjects surveyed feel that they have a close relationship with another person or persons, or have an intimate relationship with a partner. This category, likewise, contains five items. The authors of the scale noted that it has a high-reliability ratio $(\alpha=0.87 \sim 0.90)$. The scale is being applied worldwide. Validated versions in Spain (Yarnoz-Yaben, 2008), Poland (Adamczyk \& DiTommaso, 2014), Iran (Jowkar, 2012), Brazil (Guimarães, et al., 2019), Bulgaria (Alexandrova, 2015), and Turkey (Cecen, 2007).

\section{Data and methodology \\ Participants}

A total of 2092 people participated in the study. Of these, 383 were in early and middle adulthood (2055 years) and 1709 were in late adulthood (over 60 years). The data were collected over a decade and ran in two stages: a study on the psychometric capabilities of the elderly test (over 60 years) was conducted in 2010-2014, and in 2019-2020 the survey was conducted among younger respondents (20- 55 years).

\section{Method}

SELSA-S (The Social and Emotional Loneliness Scale for Adults - Short Form) (DiTommaso, Brannen \& Best, 2004). It contains 15 items divided into three subscales: social loneliness (e.g., "I do not have any friends who understand me, but I wish I did."); emotional loneliness (e.g., I "feel alone when I am with my family") and romantic loneliness (e.g., "I have an unmet need for a close romantic relationship"). Some of the items on the scale are reversed.

It also contains a sociodemographic questionnaire containing information on gender and age.

\section{Procedure}

After examining both the first and reduced versions of the scale, a decision was made to choose the short version, as it is more convenient and appropriate for exploring the elderly. The scale has been translated from English to Bulgarian by several independent translators. After the Bulgarian translation was created, the scale was again translated from Bulgarian to English by another translator. After comparing the original scale with the Bulgarian translation by a psychologist whose mother language is English, the scale was tested on a small number of 50 elderly people to see if it was effective and to indicate whether it could be subject to adaptation and validation in Bulgarian conditions. Older people responded to the questions within 20 minutes, strongly indicating that they understood the instructions, the meaning of the statements and that the scale elements needed no change. The scale was then completed during five years (first study) by 1709 people (all of whom were over 60 years of age) and another two years (second study) by 383 people who were in early and middle adulthood (20-55 years).

\section{Results}

To determine the psychometric values of SELSA-S (DiTommaso, Brannen \& Best, 2004) on the Bulgarian sample, the data were subjected to statistical analysis using the SPSS 20 program and factor analysis, reliability analysis, correlation analysis, and comparative analysis by gender and age factors.

Factor analysis

An exploratory factor analysis was first performed. Its function was to determine what was the SELSA factor matrix for the Bulgarian sample. The Kaiser-Mayer-Ollkin index was first examined to indicate whether the sample was adequate to be subjected to factor analysis. In our case, this index was high and the factor analysis was possible $\left(\mathrm{KMO}=0.820 ; \chi^{2}(105)=2530.180 ; \mathrm{p}<0.001\right)$. The factor 
weights of all the verses were above 0.30 , which also indicated that the claims were clear and well understood by the subjects examined. However, for the Bulgarian sample, it was found that the fourfactor solution - not the three-factor solution - explained $63.26 \%$ of the total variance. The first factor explained $31.27 \%$ and it covered five items: $1,4,8,11$, and 12 . They were fully consistent with the SELSA Emotional Loneliness scale. The second factor explained $16.09 \%$ and it covered five items: 2, 5, 7, 9, and 13. They were completely in line with the Social Solitude scale on the original scale. A third factor explained $8.35 \%$ and here fell 3.6, 14 items. The fourth factor explained $7.55 \%$ and it covered only two items: 10 and 15. Factors 3 and 4 corresponded to the SELSA Romantic Loneliness Scale, but in the Bulgarian context, it was evident that the subjects studied distinguished loneliness as a result of the absence of a loved one and/or partner in their lives and loneliness as a result of longing and desire for a satisfying romantic relationship. The Varimax method for the rotation of factor values for middle-aged adults compared to people over 60 years of age.

\begin{tabular}{|c|c|c|c|c|c|c|c|c|}
\hline \multicolumn{9}{|c|}{ able 1: Rotated Component Matrix of SELSA-S } \\
\hline & \multicolumn{4}{|c|}{\begin{tabular}{l|l}
\multicolumn{2}{c}{ Adult } \\
2 & 3
\end{tabular}} & 1 & \multicolumn{2}{|c|}{\begin{tabular}{l|l}
\multicolumn{3}{|c}{ Elderly } \\
2 & 3
\end{tabular}} & 4 \\
\hline 1. I feel alone when I am with my family & .527 & & & & .483 & & & \\
\hline 2. I feel part of a group of friends & & .664 & & & & .644 & & \\
\hline $\begin{array}{l}\text { 3. I have a romantic partner with whom I share my most } \\
\text { intimate thoughts and feelings }\end{array}$ & & & .820 & & & & .907 & \\
\hline 4. There is no one in my family I can depend on for & .729 & & & & .691 & & & \\
\hline $\begin{array}{l}\text { support and encouragement. I wish there were. } \\
\text { 5. But my friends understand my motives and reasoning }\end{array}$ & & .763 & & & & 664 & & \\
\hline $\begin{array}{l}\text { 6. I have a romantic or marital partner who gives me the } \\
\text { support and encouragement I need. }\end{array}$ & & & .831 & & & & .901 & \\
\hline $\begin{array}{l}\text { 7. I don't have any friends who share my views, but I } \\
\text { wish I did }\end{array}$ & & .733 & & & & 650 & & \\
\hline 8. I feel close to my family & .629 & & & & .834 & & & \\
\hline 9. I am able to depend on my friends for help. & & .767 & & & & .683 & & \\
\hline 10. I wish I had a more satisfying romantic relationship. & & & & .840 & & & & .857 \\
\hline 11. I feel part of my family. & .766 & & & & .837 & & & \\
\hline 12. My family really cares about me. & .759 & & & & .844 & & & \\
\hline $\begin{array}{l}\text { 13. I do not have any friends who understand me, but I } \\
\text { wish I did. }\end{array}$ & & .714 & & & & 749 & & \\
\hline 14. I have a romantic partner to whose happiness I & & & .833 & & & & .889 & \\
\hline $\begin{array}{l}\text { contribute. } \\
\text { 15. I have an unmet need for a close romantic relationship. }\end{array}$ & & & & .806 & & & & .794 \\
\hline $\begin{array}{l}\text { Extraction Method: Principal Component Analysis. } \\
\text { Rotation Method: Varimax with Kaiser Normalization. }\end{array}$ & & & & & & & & \\
\hline a. Rotation converged in 6 iterations. & & & & & & & & \\
\hline
\end{tabular}

From Table 1 it can be seen that the factor extracts were almost identical in both age groups. This showed that the method was good and reliable to measure loneliness at any age in adulthood.

Reliability analysis (Cronbach's alpha) showed whether and to what extent the scale and subscales were reactive. Both age groups were found to have high-reliability ratios. For the Emotional Loneliness scale ( $\alpha=0.845$ in the elderly and $\alpha=0.792$ in the early and middle adulthood). The standard deviation values for both age groups were within the normal range $(\sigma=1.76 \sim 2.12)$, and there was no reason to believe that there were serious clinical manifestations of this type of loneliness. For the Social Loneliness Scale ( $\alpha=0.727$ for the elderly and $\alpha=0.789$ for the young and middleaged), the standard deviation values for both age groups $(\sigma=1.83 \sim 2.23)$ indicated a normal subscale distribution, which was an indication that the subjects surveyed were psychologically healthy. The reliability of the Romantic Loneliness scale was also high in both age groups $(\alpha=0.746$ in the elderly sample and $\alpha=0.820$ in the early and middle adulthood). The standard deviation varied as with the previous two scales $(\sigma=1.77 \sim 2.04)$, indicating a normal subscale distribution. The overall reliability of SELSA was high for both age groups $(\alpha=0.825 \sim 0.826)$. 
The determination of the test's profitability was also confirmed by internal correlations between subscales. In general, the correlations between the scales were in line with the theoretical concept of structure and the relationships between the different specifics of loneliness. Correlation analysis between the SELSA subscales showed moderate but statistically significant correlations, e.g., between "Romantic loneliness" and "Emotional loneliness" $(\mathrm{r}=0,516 ; \mathrm{p} \leq 0,001)$; between "Romantic loneliness" and "Social loneliness" $(\mathrm{r}=0.258 ; \mathrm{p}=0.007)$ and between "Emotional loneliness" and "Social loneliness" $(r=0.486 ; p \leq 0.001)$. All these interrelations proved that using the SELSA metrics the for Bulgarian sample is an appropriate method for measuring loneliness.

\section{Construct validity}

Construct validity is the correspondence between the substantive nature of a method and one or more criteria. To this end, the relationship between SELSA and gender and age factors was monitored. It was found that there was no statistically significant difference for the gender factor, but there were several for the age factor. Figure 1 shows that, on the Emotional Loneliness scale, the highest values were found for the oldest representatives in the sample $(F=8,145 ; p \leq 0,001)$, and the lowest among people up to 25 years and among people between $35-55$ years.

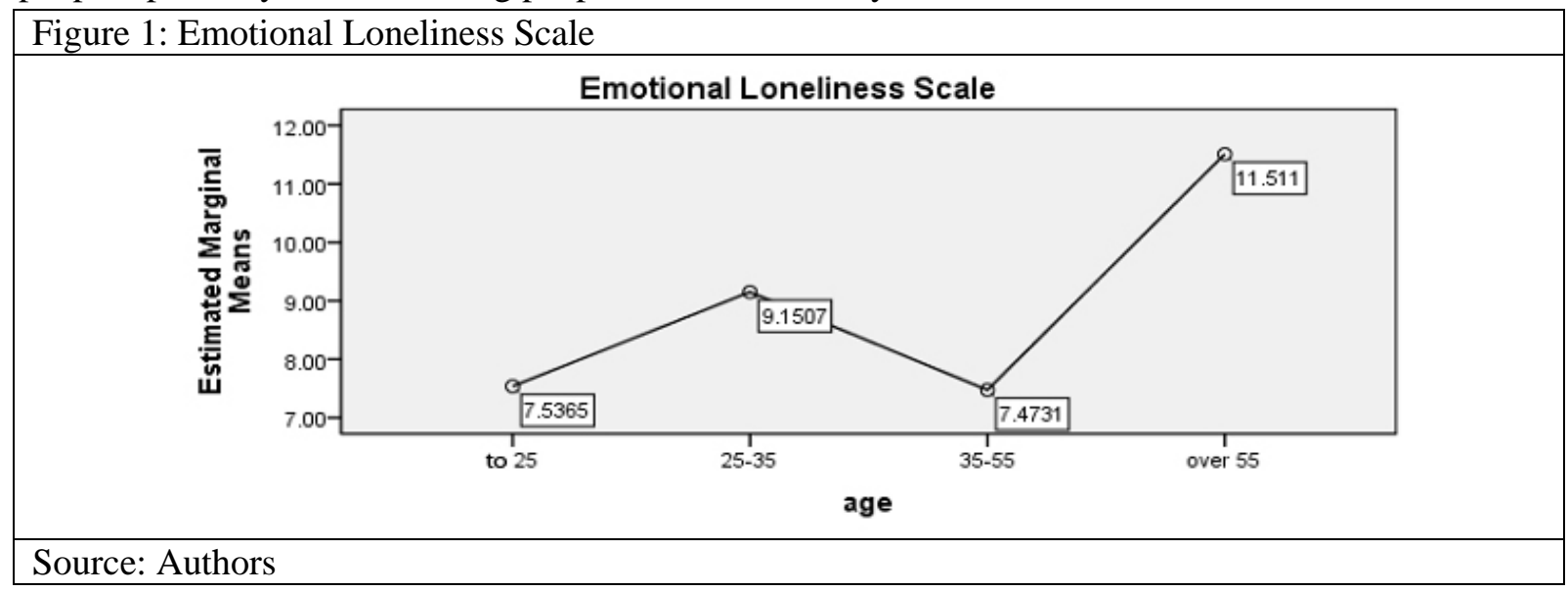

Figure 1 showed that older people were at the highest risk of experiencing emotional loneliness compared to other age groups. The family was an important factor in the well-being of older people. It was important for them to feel that their children and / or grandchildren were in contact with them. But when they felt that their younger relatives communicated with them out of duty, they might look for alternative communication options such as neighbors, friends, and thus dealt with loneliness.

Similar results were obtained on the Social Loneliness scale $(F=6,758 ; p \leq 0,001)$. It was important to note that older people prioritized their relationships with their acquaintances and friends. At the end of life, when a person was more likely to lose his or her spouse, he or she sought to make up for this lack of contact with friends within his or her social environment. Also, retirement could deepen the loneliness experience of the elderly, as they lost a significant number of contacts with their colleagues. It is important to clarify that elderly people highly appreciated not the number or size of social contacts, but their subjectively perceived quality of their social relationships.

This was not the case with the Romantic Loneliness scale $(\mathrm{F}=8,348 ; \mathrm{p} \leq 0,001)$ (Fig. 2).

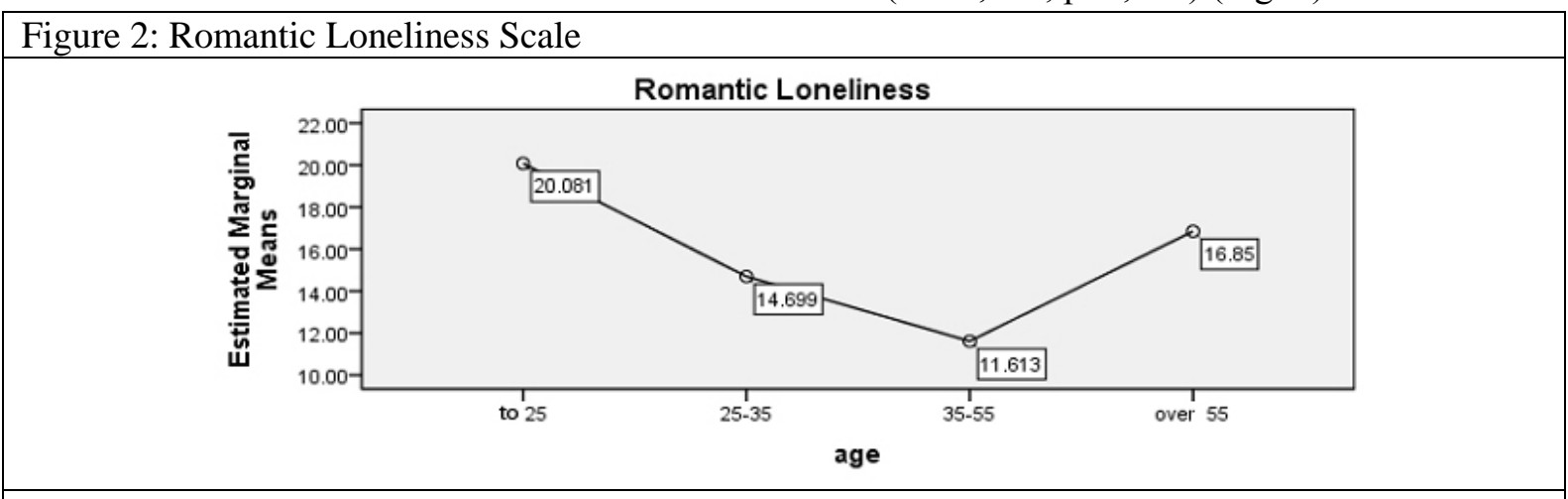

Source: Autors 
It showed that the youngest part of the sample had a longing for a close and cordial relationship with an intimate partner. This result illustrated that loneliness was also present among younger people and was not an experience specific only to the elderly, although the second most affected group was that of the elderly. Young people in their quest for a promising career were less likely to have an intimate partner, while older people were more likely to lose their partner. The lowest was the level of romantic loneliness in people between 25-55 years, because they were most likely to be married, and this, in turn, prevented them from experiencing loneliness.

The study found no statistically significant gender differences.

\section{Discussion}

The study found that the Bulgarian version of SELSA-S is a reliable and valid scale for measuring loneliness. This can be seen from the high Chronbach coefficients for each subscale, both in the sample of young and old people. This shows that these three subscales are relatively independent of each other. However, the factor analysis showed a four-factor solution, and a three-factor one as in DiTommaso \& Spinner (1993). The items from the scale "Romantic loneliness" are divided into two subscales: one refers to the desire and longing for a close partner; and the other for a romantic relationship. The constructive validity showed that there were statistically significant differences between the sample of young people and the sample of old people on the "Emotional loneliness" and "Romantic loneliness" subscales. Older people experience higher levels of emotional loneliness. As the years go by, older people face life events such as widowhood, their children have their own families, and they often spend their last years alone, which is a prerequisite for their experience of emotional loneliness. Younger people tend to experience romantic loneliness and difficulties with finding a partner.

\section{Limitations of the study}

This SELSA psychometric study has its limitations. For example, it does not trace the relationship between SELSA and other scales for measuring loneliness, i.e., lack of criteria validity. The reason for this is that currently in Bulgaria there are no other validated methods measuring loneliness. It is also advisable to support the results with longitudinal studies to confirm the sustainability and reliability of the scale. Another limitation of the present study is that construct validity is briefly presented, that is, in the future we aim to see how the SELSA subscales correlate with other scales that would confirm the capabilities of this scale, e.g. the link between the SELSA subscales and coping strategies or wellbeing / life satisfaction.

\section{Conclusion}

Studies on psychometric indicators of a scale are efficient because they provide an indication of the value of the method used. SELSA is a suitable and reliable tool for the Bulgarian context. A fourfactor scale solution was found, as well as high reliability for both the entire scale and the individual subscales. Understanding loneliness and its variants is a prerequisite for good social and health practices. When there is a qualitative scale to measure and monitor periodically the level of loneliness among people, then it is also possible to make valuable recommendations for overcoming it. This scale can help counseling or clinical psychology professionals recognize when a person is not threatened by the experience of loneliness and its effects on humanity and when loneliness begins to become harmful and pathological for people's mental health and accordingly, take appropriate preventive measures to overcome or minimize them.

\section{Acknowledgments}

This paper was supported by the project of Bulgarian Research Fund, Project No. KP06-Russia14, entitled "Loneliness vs. independence across the lifespan: Perspectives and insights from Bulgaria and Russia".

\section{References}

Adamczyk, K., \& DiTommaso, E. (2014). Psychometric Properties of the Polish Version of the Social and Emotional Loneliness Scale for Adults (SELSA-S). Psihologijske teme, 23(3), 327-341.

Aleksandrova, N. (2015) Malka knizhka za golyamata samota [A little book about great loneliness]. Sofia: Petko Venedikov Publ., 130 p. (In Bulgarian)

Alexandrova, N. (2019). Concepts of researching the loneliness of elderly, Psychology in Education, 2019, vol. 1, no. 2, 176183 DOI: $10.33910 / 2686-9527-2019-1-2-176-183$ 
Cecen, A. (2007). The Turkish short version of the Social and Emotional Loneliness Scale for Adults (SELSA-S): Initial development and validation. Social Behavior and Personality: An international journal, 35(6), 717-734

Davidson, S.\& Rossall, Ph. (2015). Age UK Loneliness Evidence Review. Available from:

https://www.ageuk.org.uk/globalassets/age-uk/documents/reports-and-publications/reports-and-briefings/health-wellbeing/rb_june15_lonelines_in_later_life_evidence_review.pdf /

DiTomasso, E., \& Spinner, B. (1993). The development and initial validation of a social and emotional loneliness scale for adults (SELSA). Personality and Individual Differences, 14(1), 127-134. https://doi.org/10.1016/0191-8869(93)90182-3

DiTommaso, E., Brannen, C., Best, L. (2004) Measurement and validity characteristics of the short version of the social and emotional loneliness scale for adults. Educational and Psychological Measurement, vol. 64, no. 1, pp. 99-119. https://doi.org/10.1177/0013164403258450

Guimarães, A.L.L., Fonsêca, P.N., Machado, G.M.A., Guimarães, C.L.C., \& Silva, P.G.N. (2019). Social and Emotional Loneliness Scale: psychometrics evidences in the Brazilian northeast. Ciencias Psicológicas, 13(2), 283 - 295. https://doi.org/10.22235/cp.v13i2.1885

Jowkar, B. (2012). Psychometric properties of the short form of the social and emotional loneliness scale for adults (SELSAS). Journal of Behavioral Sciences, 5(4), 311-317.

Mushtaq, R., Shoib, S., Shah, T., \& Mushtaq, S. (2014). Relationship between loneliness, psychiatric disorders, and physical health? A review on the psychological aspects of loneliness. Journal of clinical and diagnostic research: JCDR, 8(9), WE01WE4. https://doi.org/10.7860/JCDR/2014/10077.4828

Neill-Hall, J. (2013). Family doctors ill-equipped for loneliness epidemic. London, UK: Campaign to End Loneliness; Available from: www.campaigntoendloneliness.org/wp-content/uploads/downloads/2013/11/FINAL-GP-Polling-PR15.11.13.pdf.

Shevchenko, V. I., Mikheyeva, A. R. (2014). Odinokiye zhenshchiny srednego vozrasta: samovospriyatiye i vospriyatiye drugimi zhenshchinami // Vestn. Novosib. gos. un-ta. Seriya: Sotsial'no-ekonomicheskiye nauki. T. 14, 1. S. $192-201$.

Tiwari S. C. (2013). Loneliness: A disease? Indian journal of psychiatry, 55(4), 320-322.

Yanguas, J., Pinazo-Henandis, S., \& Tarazona-Santabalbina, F. J. (2018). The complexity of loneliness. Acta bio-medica: Atenei Parmensis, 89(2), 302-314. https://doi.org/10.23750/abm.v89i2.7404

Yarnoz-Yaben, S. (2008). Adaptación al castellano de la escala para la evaluación de la soledad social y emocional en adultos SESLA-S. International Journal of Psychology and Psychological Therapy, 8(1), 103-116.

https://www.redalyc.org/pdf/560/56080109.pdf 